\title{
PERAN MOTIVASI DALAM UPAYA MENINGKATKAN DISIPLIN KERJA KARYAWAN (Studi pada Waroeng SS Spesial Sambal Cabang BSD Tangsel)
}

\author{
Pusporini Palupi Jamaludin, Depi Septiawan, \\ dosen01399@unpam.ac.id
}

\begin{abstract}
ABSTRAK
Penelitian ini bertujuan untuk mengetahui bagaimana peran motivasi di Waroeng SS Spesial Sambal cabang BSD-Tangsel, untuk mengetahui bagaimana tingkat disiplin kerja di Waroeng SS Spesial Sambal cabang BSD-Tangsel, untuk mengetahui peran motivasi dalam upaya meningkatkan disiplin kerja karyawan pada Waroeng SS Spesial Sambal cabang BSD-Tangsel.

Metode penelitian yang digunakan dalam penelitian ini adalah metode kualitatif. Dengan pendekatan enterpretatif. Teknik pengambilan sampel yang digunakan teknik non probability sampling yaitu purposive sampling. Teknik pengumpulan data menggunakan observasi, wawancara, dokumentasi dan triangulasi. Teknik analisis data menggunakan pengumpulan data, reduksi data, penyajian data dan kesimpulan.

Berdasarkan hasil pengujian, karyawan diperusahaan sudah mendapatkan motivasi secara tidak langsung seperti jenjang karir dan sudah cukup mendapatkan motivasi secara langsung seperti penghargaan bagi karyawan terbaik akan tetapi masih kurangnya pengetahuan karyawan tentang penghargaan ini. Disiplin kerja diperusahaan telah dilaksanakan dengan baik tetapi belum opimal, karena masih ada beberapa karyawan yang belum melaksanakan disiplin kerja dengan baik.
\end{abstract}

\section{Kata Kunci: Motivasi, Disiplin Kerja}

\begin{abstract}
This research aims to determine the role of motivation in Waroeng SS Special Sambal branch BSD-Tangsel, to determine the level of work discipline at Waroeng SS Special Sambal branch BSD-Tangsel, to determine the role of motivation in efforts to improve employee work discipline at Waroeng SS Special Sambal branch BSD-Tangsel.

The research method used in this research is a qualitative method. The sampling technique used was non probability sampling technique, namely purposive sampling. Data collection techniques using observation, interviews, documentation and triangulation. Data analysis techniques used data collection, data reduction, data presentation and conclusions. Based on the test results, employees in the company have received indirect motivation such as career paths and have had enough direct motivation such as awards for the best employees, but employees still lack knowledge of this award. Work discipline in the company has been implemented well but has not been optimal, because there are still some employees who have not implemented work discipline properly.
\end{abstract}




\section{Keywords: Motivation, Work Discipline}

\section{I . PENDAHULUAN}

\section{A. Latar belakang Penelitian}

Organisasi merupakan sistem dan kegiatan manusia yang bekerja secara bersama-sama. Sejalan dengan itu, organisasi di katakan sebagai suatu koordinasi rasional kegiatan sejumlah orang untuk mencapai beberapa tujuan umumnya melalui pembagian pekerjaan dan fungsi melalui hirarki otoritas dan tanggung jawab sumber daya manusia. Maka di butuhkanlah manajemen sumber daya manusia untuk mengatur tenaga kerja yang ada di dalam organisasi sehingga terwujud tujuan organisasi dan kepuasan kerja karyawan.

Untuk mendapatkan sumber daya manusia yang di harapkan organisasi dapat memberikan andil positif terhadap semua kegiatan perusahaan dalam mencapai tujuannya, setiap karyawan di harapkan memiliki motivasi kerja yang tinggi yang di harapkan nantinya akan meningkatkan disiplin kerja. Motivasi merupakan hal yang sangat penting untuk di perhatikan oleh pihak manajemen bila mereka menginginkan setiap karyawan dapat memberikan kontribusi positif terhadap pencapaian tujuan perusahaan, karena dengan motivasi, seorang karyawan akan memiliki semangat yang tinggi dalam melaksanakan tugas yang di bebankan kepadanya.

Waroeng SS Spesial Sambal cabang BSD Tangsel adalah salah satu perusahaan yang bergerak di bidang kuliner. Waroeng SS Spesial Sambal cabang BSD Tangsel dalam kegiatan

Dalam metode kualitatif teknik pengumpulan data di lakukan secara triangulasi (gabungan), analisis data usahanya berusaha meningkatkan motivasi serta mengharapkan prestasi kerja terhadap semua aktivitas yang di lakukan oleh karyawannya dengan baik. Hal ini terlihat pada penyelesaian pekerjaan yang tidak tepat waktu, seringnya karyawan tidak masuk kerja, seringnya karyawan terlambat datang ke tempat kerja, terlalu santai dalam melaksanakan pekerjaan yang di berikan oleh atasan. Oleh sebab itu di perlukan motivasi kerja untuk membina kesadaran dan disiplin kerja karyawan. Dalam hal ini Waroeng SS Spesial Sambal cabang BSD Tangsel, sudah seharusnya memiliki karyawan yang penuh semangat dan bermotivasi tinggi dalam bekerja dan melakukan pekerjaannya secara efektif dan efisien.

motivasi merupakan masalah yang sangat penting dalam suatu perusahaan, karena dapat meningkatkan disiplin kerja karyawan. Sehingga kemampuan manajemen dalam memberikan motivasi akan sangat menentukan keberhasilan atau kegagalan dalam pencapian tujuan perusahaan.

\section{METODE PENELITIAN}

Metode penelitian yang di gunakan dalam penelitian ini yaitu penelitian kualitatif secara deskriptif dengan pendekatan fenomologi. Menurut Sugiyono (2017:9) "metode penelitian kualitatif adalah metode penelitian yang berlandaskan pada filsafat postpositivme, di gunakan untuk meneliti pada kondisi obyek yang alamiah, (sebagai lawannya adalah eksperimen) dimana peneliti adalah sebagai instrumen kunci,

bersifat induktif/kualitatif, dan hasil penelitian kualitatif lebih menekankan makna dari pada generalisasi”. 
Populasi di Waroeng SS Spesial Sambal cabang BSD-Tangsel berjumlah 42 orang. Tetapi dalam penelitian kulitatif tidak menggunakan istilah populasi, tetapi dinamakan "social situation". Sampel dalam penelitian kualitatif bukan di namakan responden tetapi narasumber, penentuan sampel dengan melihat karakteristik peneliti. Karakteristik yang di ambil peneliti

\section{HASIL PENELITIAN}

\section{Motivasi Karyawan pada}

\section{Waroeng SS Spesial Sambal cabang}

\section{BSD Tangsel}

motivasi adalah sesuatu yang menimbulkan semangat atau dorongan kerja". Motivasi juga merupakan bagian dalam meningkatkan tingkat disiplin kerja karyawan. Dengan demikian motivasi memiliki manfaat positif dalam upaya meningkatkan disiplin kerja karyawan.

Jawaban dari Sela selaku Staff Operasional."Udah sesuai harapan ya, tapi motivasi yang saya harapkan dari pimpinan kalo yaitu pemberian reward kalo saya bekerja dengan baik." (Sela/22/07/2020)

\section{Informan Utama I}

Kemudian jawaban dari Royani selaku Staff Operasional."Untuk pemberian motivasi dari pimpinan sudah sesuai dengan harapan saya." (Royani/22/07/2020)

\section{Informan Utama II}

Selanjutnya jawaban dari Rian Kurniawan selaku Asisten Operasional. "Sudah sesuai harapan, tapi info tentang penghargaan bagi karyawan terbaik tidak yaitu di lihat dari masa kerja, dengan masa kerja yang di ambil minimal selama lima tahun keatas yang di harapkan dapat membantu penulis. Kemudian di lihat dari jabatan yang sedang di tempati saat ini dan yang terakhir di lihat dari pendidikan terakhir rata-rata SMA atau SMK. Sampel yang di ambil oleh penulis yaitu sebanyak 8 orang narasumber, 6 orang sebagai informan utama, 2 orang sebagai informan triangulasi.

di sampaikan di awal saat perjanjian kerja, jadi ada karyawan yang menganggap motivasi dari pimpinan belum sesuai harapan."

(Rian Kurniawan/22/07/2020)

\section{Informan Utama III}

Kemudian jawaban Agung Prasetyo selaku Staff Khusus SDM.

"Sudah, akan tetapi motivasi dari segi penghargaan untuk karyawan terbaik tidak di sampaikan di awal sehingga berakibat kepada sebagian karyawan yang berpikir bahwa tidak ada reward untuk karyawan terbaik dan ini mempengaruhi motivasi dari karyawan itu." (Agung Prasetyo/22/07/2020)

\section{Informan Utama IV}

Jawaban Fadilah Febriyanti selaku Staff Operasional.

"Motivasi dari pimpinan sesuai sama yang saya harapkan."

(Fadilah Febriyanti/22/07/2020)

\section{Informan Utama $V$}

Lalu jawaban Muhammad Yanuar Pratama selaku Staff Pelayanan.

"Belum sesuai harapan karena harapan saya pimpinan memberikan penghargaan kepada setiap karyawan yang telah bekerja dengan baik." (Muhammad Yanuar Pratama/22/07/2020)

Informan Utama VI 
Dari penjelasan informan utama I sampai VI, bahwa banyak yang menjawab sudah sesuai dengan harapan, akan tetapi motivasi yang di berikan oleh pimpinan dari segi penghargaan untuk karyawan terbaik tidak di sampaikan di awal sehingga berakibat kepada sebagian karyawan yang berpikir bahwa tidak ada reward untuk karyawan terbaik dan ini mempengaruhi motivasi dari karyawan.

Setelah penulis melakukan wawancara dengan informan utama maka penulis mengajukan pertanyaan kepada triangulasi yang terkait dengan

"Apakah terdapat hambatan dalam memotivasi karyawan?".

Jawaban dari Febriyan Yolanda Putra selaku Kepala Cabang

"Oh banyak pastinya hambatan, karena banyak yang personil itu atau mungkin karyawan bekerja karena memang dia mengharapkan gaji aja sekedar syarat untuk menggugurkan tanggung jawab mereka, mereka bekerja ya sesuai apa adanya ga melihat contohnya ni saya harus bekerja keras supaya saya itu mendapatkan karya yang baik itu mereka ga ada tapi ada yang emang mereka mencari pengen mencapai seperti itu akhirnya mereka bekerja keras, mungkin hambatannya itu tergantung personil itu sendiri dia itu mau usaha mengejar karir dia atau enggak." (Febriyan Yolanda Putra/30/09/2020)

\section{Triangulasi I}

Selanjutnya jawaban dari Sulaeman selaku Wakil Kepala Cabang.

"Iya udah pasti, ketika kita memberi motivasi terhadap karyawan pada beberapa orang ini susah nangkep ada yang cepet nangkep, jadi setiap orang itu memiliki penangkapan masing-masing tergantung dari kita cara penyampaian sama memahami sifat dia." (Sulaeman/30/09/2020)

\section{Triangulasi II}

Dari penjelasan triangulasi I dan II, bahwa masih terdapat hambatan dalam memotivasi karyawan seperti ketika pimpinan memberikan masukkan terhadap karyawan ada beberapa yang tidak memahami, adanya karyawan yang hanya sekedar menggugurkan kewajibannya saja sehingga tidak memiliki keinginan untuk menjadi lebih baik lagi.

\section{Disiplin Kerja Karyawan pada Waroeng SS Spesial Sambal cabang BSD Tangsel}

Jawaban Sela selaku Staf Operasional. "Melakukan yang diinstruksikan, kita harus sesuai dengan yang diinstruksikan jangan ngelawan, apa aja yang diinstruksikan harus kita jalanin." (Sela/22/07/2020)

Informan Utama I

Lalu Jawaban Royani selaku Staf Operasional.

"Jadi kalau di Waroeng SS kan cara absensi ya, kalau kita masuk kerja jam 8 itu sebelum jam 8 itu, jam 8 kurang 15 udah sampai disini ga nyampe ngepas banget." (Royani/22/07/2020)

\section{Informan Utama II}

Selanjutnya jawaban Rian Kurniawan selaku Asisten Operasional.

"Yang pertama ada istilah tepat waktu dalam bekerja terus juga kerja lebih baik, kerjanya ga buruk ga asal-asalan ataupun beri yang terbaik untuk perusahaan kita." (Rian Kurniawan/22/07/2020)

\section{Informan Utama III}

Lalu jawaban Agung Prasetyo selaku Staf Khusus SDM.

"Kalau masalah disiplin itu kan udah jadi tanggung jawab saya disini dan bahkan saya jadi contoh disini juga harus menerapkan itu jadi dari hal kecil seperti 
contoh seperti absen jangan lupa absen, selalu saya ingetin itu buat anak-anak kalau sampai kalian lupa absen nanti kalian hari ini ga absen berarti hari ini ga bergaji jadi buat motivasi keanak-anak juga supaya dari hal kecil kita belajar disiplin." (Agung Prasetyo/22/07/2020)

\section{Informan Utama IV}

Kemudian jawaban Fadilah Febriyanti selaku Staf Operasional."Ya dengan mengikuti aturan yang ada."(Fadilah Febriyanti/22/07/2020)

\section{Informan Utama $V$}

Selanjutnya jawaban Muhammad Yanuar Pratama selaku Staf Pelayanan.

"Caranya itu mengikuti semua peraturan, mengikuti semua arahan dari atasan ataupun tidak menghilangkan SOP-SOP yang sudah ada."

(MuhammadYanuar

Pratama/22/07/2020)

\section{Informan Utama VI}

Hasil wawancara dengan informan utama I sampai VI tentang cara melakukan disiplin kerja dengan baik, banyak yang menyatakan bahwa melakukan disiplin kerja dengan baik dapat di lakukan dengan cara mengikuti peraturan yang ada di perusahaan, mengikuti arahan dari atasan dan menjalankan SOP perusahaan.

\section{V. PENUTUP}

\section{A. KESIMPULAN}

Berdasarkan hasil analisis data dan pembahasan pada uraian sebelumnya, tentang hasil-hasil observasi dan wawancara. Maka penulis mendapat kesimpulan sebagai berikut.

1. Motivasi kerja karyawan Waroeng SS Spesial Sambal cabang BSD Tangsel periode 2017-2019 terkait komunikasi bisa di katakan sudah baik
Lalu penulis mengajukan pertanyaan kepada triangulasi mengenai "Apakah karyawan telah melaksanakan disiplin kerja dengan baik?"

Jawaban Febriyan Yolanda Putra selaku Kepala Cabang.

"Kebetulan disini personil sini atau mungkin seluruh karyawan SS ya itu udah benar-benar terpilihlah, udah kita benar-benar saring mereka itu yang sudah menjalankan disiplin, jujur, sangat baik disini."

(FebriyanYolanda Putra/30/09/2020)

\section{Triangulasi I}

Selanjutnya jawaban dari Sulaeman selaku Wakil Kepala Cabang.

"Untuk Waroeng SS alhamdulillah sudah baik, ada beberapa orang saja yang mungkin tidak melaksanakan tapi ya dari kita pejabat ya terus meningkatkan supaya mereka tetap disiplin." (Sulaeman/30/09/2020)

\section{Triangulasi II}

Dari jawaban para triangulasi, menyatakan bahwa disiplin kerja telah di laksanakan dengan baik, tetapi ada yang menyatakan bahwa masih ada beberapa yang belum melaksanakan dengan baik.

karena komunikasi yang di lakukan terarah tetapi masih belum optimal karena ketika pimpinan memberikan masukkan terhadap karyawan ada beberapa yang tidak memahami, adanya karyawan yang hanya sekedar menggugurkan kewajibannya saja sehingga tidak memiliki keinginan untuk menjadi lebih baik lagi. Sedangkan untuk motivasi, karyawan Waroeng SS Spesial Sambal cabang BSD 
Tangsel sudah mendapatkan motivasi secara tidak langsung seperti jenjang karir dan sudah cukup mendapatkan motivasi secara langsung seperti penghargaan bagi karyawan terbaik, akan tetapi di sini masih minimnya informasi atau memorandum dari pimpinan terkait adanya bentuk penghargaan kepada karyawan, di awal perjanjian kerjapun tidak singgung adanya penghargaan oleh pimpinan yang membuat karyawan merasa bahwa tidak adanya reward atau penghargaan pada karyawan terbaik sesuai dengan penilaian, padahal perusahaan memberikan penghargaan tersebut. Pentingnya perusahaan untuk memberikan pengetahuan tentang informasi hak karyawan dan sebagainya guna menambah semangat dan pastinya motivasi dari pimpinan juga, agar karyawan menjadi termotivasi dan akan lebih baik dalam bekerja.

2. Disiplin kerja karyawan Waroeng SS Spesial Sambal cabang BSD Tangsel periode 2017-2019 telah di laksanakan dengan baik tetapi belum opimal, karena masih ada beberapa karyawan yang belum melaksanakan disiplin kerja dengan baik seperti dari segi absensi, masih ada karyawan yang tingkat absensinya belum sesuai dengan yang di inginkan oleh perusahaan. Dan dari segi tersebut harus lebih di tingkatkan lagi agar disiplin kerja lebih baik dan sesuai dengan yang di inginkan oleh perusahaan.
3. Peran motivasi dalam upaya meningkatkan disiplin kerja karyawan Waroeng SS Spesial Sambal cabang BSD Tangsel periode 2017-2019, untuk motivasi sudah di berikan yaitu berupa penghargaan / reward untuk karyawan teladan, tetapi cara yang di gunakan pimpinan dengan mengamati karyawan dan masukan yang positif dari pimpinan agar karyawan bekerja lebih semangat lagi. Motivasi memiliki peran dalam upaya meningkatkan disiplin kerja seperti yang di ungkapkan oleh beberapa narasumber dalam penelitian ini bahwa ketika seseorang memiliki motivasi maka akan memiliki tujuan serta semangat bekerja sehingga akan menyebabkan peningkatan disiplin kerja karyawan.

\subsection{Saran}

Dari hasil penelitian dan pembahasan yang telah di uraikan di atas, penulis dapat mengemukakan saran sebagai berikut.

1. Untuk meningkatkan motivasi kerja karyawan, Pimpinan harus fleksibel, terbuka dan dapat menyesuaikan diri dengan seluruh karyawan agar komunikasi yang di lakukan dapat tersampaikan dengan baik dan benar sehingga karyawan dapat memahami masukkan yang di berikan oleh pimpinan. Perusahan juga harus memberikan perhatian khusus terhadap pemberian penghargaan kepada karyawan terbaik. Karena hal ini dapat memberikan motivasi kepada karyawan sehingga karyawan 
akan meningkatkan kedisiplinan dalam bekerja dan berkompetisi untuk menyelesaikan tugas dan tanggung jawabnya dengan baik dan benar.

2. Untuk meningkatkan disiplin kerja, perusahaan harus rutin melakukan evalusi tentang kedisiplinan karyawan, evalusi berguna agar karyawan yang disiplin kerjanya telah baik agar tetap di pertahankan secara konsisten dan untuk karyawan yang disiplin

\section{DAFTAR PUSTAKA}

\section{Buku}

Badriyah, M. (2017). Manajemen Sumber Daya Manusia. Bandung: CV Pustaka Setia.

Effendi, S. (2015). Tata Bahasa Acuan Bahasa Indonesia. Tangerang: Pustaka Mandiri.

Fahmi, I. (2016). Teori dan Teknik Pengambilan Keputusan. Jakarta: Raja Grafindo Persada.

Hasibuan, M. (2018). Manajemen Sumber Daya Manusia. Jakarta: PT Bumi Aksara.

Mangkunegara, A. P. (2015). Manajemen Sumber Daya Manusia Perusahaan. Bandung: PT Remaja Rosdakarya.

Mangkunegara, A. P. (2016). Manajemen Sumber Daya Manusia Perusahaan. Bandung: PT Remaja Rosdakarya.

Mangkunegara, A. P. (2017). Manajemen Sumber Daya Manusia Perusahaan. Bandung: PT Remaja Rosdakarya.

Nazir, M. (2015). Metode Penelitian. Bogor: Ghalia Indonesia.

\begin{abstract}
kerjanya masih rendah di harapkan dapat lebih di tingkatkan lagi disiplin kerjanya. Peran motivasi yang di lakukan secara verbal oleh pimpinan juga di butuhkan dalam upaya meningkatkan disiplin kerja karyawan, pimpinan harus dapat memahami karyawan, fleksibel dan juga terbuka agar karyawan menerima dan memahami setiap masukkan yang di berikan oleh pimpinan.
\end{abstract}

Novitasari, E. (2017). Pengantar Manajemen Panduan Menguasai Ilmu Manajemen. Yogyakarta: Quadrant.

Nurudin. (2016). Ilmu Komunikasi Ilmiah dan Populer. Jakarta: Raja Grafindo Persada.

Pasaribu, V. L. D., Susanti, F., \& Hartuti, E. T. K. (2019). Memotivasi Siswa dan Siswi SMK Letris Indonesia di Dalam Menentukan Pilihan Untuk Melanjutkan Pendidikan Atau Bekerja Setelah Lulus Sekolah. Jurnal Pengabdian Dharma Laksana, 1(2), 161-172.

Pasaribu, V. L. D., \& Krisnaldy, K. (2018). ANALISIS KEPUASAN JAMA'AH PADA KINERJA DEWAN KEMAKMURAN MASJID AL-HIDAYAH PERIODE TAHUN 2017. KREATIF: Jurnal Ilmiah Prodi Manajemen Universitas Pamulang, 6(4), 41-51.

Pasaribu, V. L. D., Krisnaldy, K., \& Warasto, H. N. (2020). Pengaruh Gaya Kepemimpinan, Disiplin Kerja Dan Kompensasi Terhadap Kinerja Pegawai (Studi kasus 
kelurahan Pisangan
Ciputat). Jurnal Disrupsi Bisnis: Jurnal Ilmiah Prodi Manajemen, Fakultas Ekonomi, Universitas Pamulang, 3(1).

Pasaribu, V. L. D., \& Krisnaldy, K. (2020). PENGARUH GAYA KEPEMIMPINAN, DISIPLIN KERJA DAN KOMPENSASI TERHADAP HASIL KINERJA KARYAWAN KELURAHAN PISANGAN

CIPUTAT. PROCEEDINGS

UNIVERSITAS

PAMULANG, 1(1).

Priansa, S. d. (2016). Manajemen Sumber Daya Manusia. Bandung: Alfabeta.

Sinambela, L. P. (2016). Manajemen Sumber Daya Manusia. Jakarta: Bumi Aksara.

Sugiyono. (2017). Metode Penelitian Kuantitatif, Kualitatif dan $R \& D$. Bandung: Alfabeta.

Sutrisno, E. (2016). Manajemen Sumber Daya Manusia. Jakarta: Prenada Media Group.

Wibowo. (2016). Manajemen Kinerja Edisi Kelima. Jakarta: PT Raja Grafindo Persada.

Winardi. (2016). Kepemimpinan dalam Manajemen. Jakarta: PT Rineka Cipta.

\section{Jurnal}

Khasanah, N. (2016). Analisis Disiplin Kerja Pegawai pada Kantor Camat Tenayan Raya Kota Pekan Baru. Jom Fisip, Vol. 3 No. 1.

Masuku, D. (2017). Analisa Motivasi Kerja Dokter Pegawai Negeri Sipil di Kabupaten Kepulauan Sula. Jurnal MKMI, 197-204.

Taufik Akbar, S. (2017). Analisis Disiplin Kerja Karyawan Kontrak pada PT AT Indonesia Karawang. Jurnal Lentera Bisnis, Vol. 6 No. 1.

\section{Skripsi}

Bustommi, A. T. (2014). Peranan Motivasi Dalam Upaya Meningkatkan Disiplin Kerja Karyawan (Studi pada Perusahaan Tegel Malang Indah Genteng Rajawali). Malang: UIN Maulana Malik Ibrahim Malang.

Erni. (2017). Peranan Motivasi terhadap Peningkatan Disiplin Kerja Pegawai pada Kantor Dewan Perwakilan Rakyat Daerah (DPRD) Kota Palopo. Palopo: IAIN Palopo. 